which his former students and friends expressed their admiration for de Vries and his work, on the occasion of the twenty-fifth anniversary of his professorship at the University of Amsterdam. On this occasion de Vries was presented with a considerable sum of money, which was expended in the erection of a vast greenhouse, which enabled him to defy the climate of Holland, against which he had been contending for many years with anything but complete success.

The Experimental Garden at Amsterdam, as it now stands, is the result of an attempt to perfect a method of observing the origin of species.

The success of this attempt will rank as one of the greatest achievements in biology.

\section{THE SURVEY OF AFRICA.}

THE fifth volume of the account of the geodetic survey of South Africa, executed under the supervision of Sir David Gill, has now been issued. With the four volumes previously published the description of the whole work, from the southernmost point of the continent up to the Zambezi River, is thus completed. A sixth and final volume is promised, which will comprise that portion of the thirtieth meridian arc done by Dr. Rubin, carrying the survey northward from the Zambezi to a point 70 miles south of Lake Tanganyika. This will therefore round off the South African part of this great undertaking, the first idea of which was originally conceived by Sir D. Gill in 1879 . To him, together with his able lieutenant, Colonel Sir W. G. Morris, the credit of thus carrying through this immense task, in face of many political and financial difficulties, must be ascribed.

The present volume is replete with interest both to the scientific surveyor and to the student of public policy on the questions of survey and map-making. The main interest naturally centres about the introduction by Sir D. Gill, and the introductory report on the trigonometrical survey of the Transvaal by Sir W. G. Morris. The former gives a succinct history of the triangulation of South Africa, recapitulates the now well-known proposal to extend the thirtieth meridian arc through the continent, and concludes with a detailed résumé of the negotiations between the Imperial Government and the colonial authorities for the formation of a federal survey department. These extended, with intermissions, from I9OI to I904, and finally ended abortively, one colony after another deciding that they could not afford the expenditure necessary for the construction of an accurate map of their territory. The expenditure ultimately and implicitly involved by the existence of inaccurate maps or by the complete non-existence of any maps at all, being an item which does not come on the estimates for the year, is, we must perforce conclude, a subject of little concern to the politician. Otherwise, unless we are to assume that public memory is so short that a period of three or four years is sufficient to drive the most striking events out of mind, it is difficult to see how one of the main object-lessons of the South African war, the extreme costliness of bad maps, should have been so soon and so completely set aside. Sir D. Gill's account not unnaturally gives special prominence to those

1 Geodetic Survey of South Africa. Vol. v. Reports on the Geodetic Survey of the Transvaal and Orange River Colony, executed by Colonel Sir w. G. Morris, K.C.M.G. C. B. and of its connection by Capt. H. W. W. G. Morris, K. .. M.G. C. B., and of its connection by Capt. H. W. rordon, R.E., with the Greodetic Survev of Snuthern Rhodesia, with $463+16$ plates ; 6 maps. (London: Harrison and Sons, rgos.) NO. 2039, VOL. 79] parts of these proceedings which took place in Africa, with which he was directly concerned. The result is that he does less than justice to the part played by the War Office, and is apparently unaware that the proposal to carry out a complete survey of South Africa, by cooperation between the Imperial and the colonial authorities, was put forward by that office long before the date of the similar suggestion by Colonel Morris, referred to on p. I6.

The whole history of this geodetic work is a curious inversion of the general order. Usually it is the complaint of the map-maker that, whereas it is not difficult to get money from a Government department for the immediate, practical work of mapping, it is a more laborious task to persuade them of the necessity for a liberal expenditure upon the fundamental geodetic triangulation. In South Africa the exact reverse of this has been the case, and we have the anomalous position of a complete triangulation system without the resulting maps; even as yet it is only in the case of the Orange River Colony and partially in Cape Colony that any of the maps of the country are based upon the positions of the geodetic points.

Of the technical part of the report the most interesting is undoubtedly the account of the base measurements carried out with invar wires hanging freely, at a constant tension, between low tripod supports. Five bases in all, totalling a length of 70 miles, were measured. Each was gone over with the wire three times, and the apparent probable error varied from I part in $\mathrm{I}, 000,000$ at the Belfast base, where the staff was inexperienced, down to nearly I part in $7,000,000$ in the most favourable case. Sir D. Gill maintains that, with a trained staff, a base can be measured in this way with an actual final uncertainty of less than $I$ part in $r, 000,000$ - say, I inch in ${ }^{5} 5$ miles-a contention apparently justified by the figures. The rate of progress, including the time spent on the wire comparison with the standard bars, averaged 475 yards per day, and the cost was high-r53l. per mile of base. In view of this, and in view of the fact that a limiting error of I part in $1,000,000$ implies a much higher degree of precision than that attained by the angular observations, it would seem more practical, for similar work in the future, to make the bases both shorter and less accurate, and, therefore, cheaper and more rapidly executed. This would have the effect of preserving that balance between the degrees of precision of the different parts of the work so essential to the economical conduct of a cycle of physical operations.

The horizontal angles were observed with the Io-inch Repsold theodolite, the probable error of a single angle being found to be $\mathrm{o}^{\prime \prime} \cdot 30$ with eight changes of zero, or $0^{\prime \prime} .39$ with four only. It is remarked that as these figures closely coincide with those previously reached in Cape Colony and Natal with the same instrument, they probably represent the highest possible degree of precision attainable under the special climatic conditions and with the instrumental means available. So far as the observing end of each line is concerned this is possibly true, but it is questionable whether the results might not have been improved, with no sacrifice of time or money, if a better pattern of beacon had been employed. The tripod or quadripod beacon, forming from any distant point a double cone, with vertex at the centre, of sufficient height to enable the theodolite or heliostat to be centred without disturbing the legs, is an altogether preferable form to the pole beacon actually used.

E. H. H. 